\title{
SERC cuts hard to avert $£ 40$ million cash crisis
}

\section{- Research grants, studentships frozen - 'Big science' projects under review}

\section{London \& Cambridge}

British science was last week plunged into crisis as the Science and Engineering Research Council (SERC), the largest funding body for UK civil science, postponed its current round of research grants and studentships, and placed a freeze on staff appointments, to avoid a predicted shortfall of $£ 40$ million in 1991-92. Large projects agreed in principle, but not yet funded, including an 8-metre optical telescope and a gravity wave observatory, now seem certain to be delayed.

SERC's financial crisis, like that which has emerged at the Medical Research Council (MRC) in recent weeks (see Nature 348, 184; 15 November 1990), is blamed largely on higher-than-expected inflation and pay settlements. The disclosure of the council's dire financial position follows the confirmation that the Agricultural and Food Research Council (AFRC) will shed some 380 research staff by the end of the financial year as part of its continuing restructuring, and the University of Bristol's decision to freeze new appointments and equipment purchase, to reduce an estimated deficit of $£ 4$ million in the current year.

A small group of council members will meet over the coming months to consider further measures needed to resolve SERC's finances. But the council's new chairman, Sir Mark Richmond, visiting Cambridge last Friday (23 November) with Education and Science Secretary Mr Kenneth Clarke to open a 32-metre radiotelescope, also promised a longerterm broad review of SERC's activities. Richmond wants to reduce spending tied up in 'big science' projects and international collaborations so that small research grants and studentships can be expanded.

Richmond used the telescope opening to attack government policy on science and the universities. The current university funding crisis (see Nature 348, 3; 1 November 1990) could "ring the death knell" for the universities' support for large science projects, he said. (The University of Manchester, where Richmond was vice-chancellor until October, currently provides $£ 800,000$ a year for radioastronomy at Jodrell Bank, he pointed out.) SERC's plans to fund an 8metre optical telescope have been sent "sprawling" by the disappointingly low science budget for 1991-92 (see Nature 348, 183; 15 November 1990), Richmond added.
Clarke sought to absolve himself from blame by pointing out that he had recently "inherited" the government's science spending plans, after his transfer from the Department of Health, but repeated the claim that the 1991-92 budget is a "realterms level settlement". After the ceremony, Richmond said that inflation is certain to mean a cut in the amount of science that can be supported: "The Secretary of State is wrong".

Richmond declined to speculate in a "knee-jerk reaction" whether his longterm review will cut back SERC's own laboratories to release money for research grants. But he said that SERC must negotiate tougher agreements to control spending on large international projects. The science budgets of CERN (the European particle physics centre) and the European Space Agency will be discussed in December. Britain's contributions to both are paid through SERC's budget, and fluctuations in international exchange rates can squeeze SERC's domestic spending. In 1987, the problem was so severe that Britain came very close to pulling out of CERN.

Frequent reviews of grants to SERC's Interdisciplinary Research Centres (IRCs), introduced under the previous chairman, Sir William Mitchell, to provide a focus for work that may eventually yield commercial results, are also likely. Three new IRC grants, totalling some $£ 18$ million, are among the projects now in abeyance. Richmond said that he is unhappy with the present arrangement, where a new IRC can receive guaranteed funding for six years. He also hinted that SERC may introduce a rigid cash limit on all research grants, rather than linking their value to inflation.

But the most important change in the expected upheaval within SERC is in the balance between spending on 'big science' projects, such as astronomy and highenergy physics, and smaller research grants. Unlike his predecessors, Richmond comes from a 'small science' background in biology. "Big old projects" will have to be cut if "big new projects" are to be started, Richmond said.

During the summer, the Advisory Board for the Research Councils suggested to Mr John MacGregor, the previous Education and Science Secretary, that SERC's support for 'big science' should be reviewed. But this is thought to have been opposed by the then Mitchellled SERC.
The other research councils have no plans to follow SERC and the MRC and suspend their current grant rounds. Professor John Knill, chairman of the Natural Environment Research Council (NERC), says that NERC's financial management is such that it would never find itself in that position.

But SERC staff say that the council's current financial plight should not be taken as evidence of lax management. To a greater degree than for the other research councils, the vast majority of SERCsupported scientists are in the universities, rather than research council laboratories. This means that SERC finds it very difficult to account for future pay settlements in its plans.

Peter Aldhous

\section{Methyl chloride gas implicated}

\section{Washington}

To the list of human activities that destroy the ozone layer can now be added lighting a campfire. 'Biomass burning' - the combustion of wood, straw or other natural fuel - releases large amounts of methyl chloride, which, as a chlorine-based gas, has many of the ozone-attacking properties of the well-documented chlorofluorocarbons. Human activity, mostly in the developing countries, pumps some 2-5 million tonnes of methyl chloride into the atmosphere each year, accounting for 5 per cent of the total concentration of ozone-

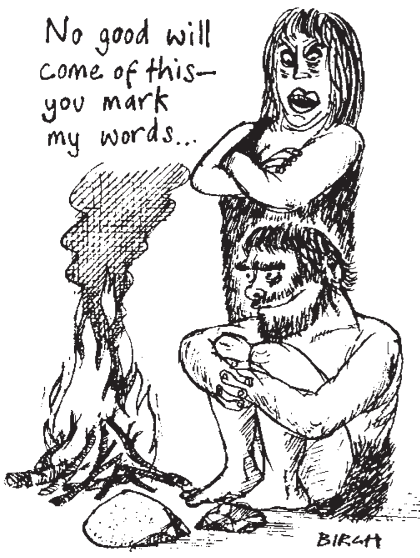

destroying chemicals in the troposphere, according to a recent report from the Maryland-based Institute for Energy and Environmental Research.

Although the chlorofluorocarbonseliminating Montreal Protocol will force the largest reduction in ozone-destroying gases, its priorities are chiefly focused on emissions that come from the developed countries, says Arjun Makhijani, one of the authors of the report. In the developing world, methyl chloride represents some 26 per cent of total ozone-unfriendly emissions.
Christopher Anderson 